\title{
SUBSTITUTE FUNCTIONS OF THE BLIND AND THE DEAF AND BLIND*
}

\author{
BY \\ LUDWIG COHN
}

Rotterdam

BLINDNESS was and still is considered the most serious of defects, and of all those suffering from a bodily infirmity the blind are the invalids who are most pitied by their fellow-men. But if you ask those who are both deaf and blind which defect is the most difficult to bear, their answer is without hesitation: deafness. And, indeed, the lack of sight can be offset to such a high degree by the other senses, that a normal and efficiently trained blind person is able to live and to work like a man who can see.

That is what the oculist, who is the first to be asked for advice, ought to know when he can give a patient no hope of retaining his sight, for thus he will be able to help the patient by relieving him of the paralysing fear of impending blindness.

J. W. Klein of Vienna invented in 1804 a primary script for the blind based on capitals shown in relief, and in 1829 Louis Braille of Paris, who was himself blind, gave to the blind their most precious possession, the script based on the 6-dots system which was easier and quicker to read. Teaching the blind then made rapid progress. By means of tin matrices the multiplication of books, maps, and pictures was made possible. Nearly every language has its Braille-shorthand, and big Braille libraries are found in every country; monthly periodicals are produced, and the Braille music-script has made possible the publication of musical scores.

A very important subject is the development of a sense of form by teaching the blind to model objects which they have learned to know by handling them.

There is very little, apart from light and colour which are perceptible only to the eye, that the blind cannot learn. When the well-known American Helen Keller writes of "the sulphur-yellow thunder-sky", or when a man born blind says "the steeple of our church is reflected in the crystal water of the brook" or speaks of "sky-blue forget-me-nots and dark-blue violets", these are only correct reproductions of what they have heard and assimilated.

One substitute for the eyes is the sense of feeling, especially in the fingertips, which can be developed to a very high degree. As to myself, I can read Braille well with gloves on, even thick leather ones. It cannot be emphasized

-Received for publication May 17, 1954. 
enough that no finger is too old or too horny to learn to feel accurately. I have taught many people older than 65 years, among them a woman of 75 years and a man of 80 , and I also had among the blind of the first world war a patient whose hands were hardened by manual work.

The second substitute function is the sense of hearing. The blind listen far more accurately than those who see, because their sense of hearing is of far more use to them. Sounds speak a different language to the blind, especially the sounds of nature; the wind through the tops of the trees, the waves on the beach, and the peals of thunder. It is significant that in the dreams of the blind these sounds often occur, which is the consequence of their dreaming acoustically.

Through the cooperation of the ear the blind can form a more or less correct image of their direct environment, in which a quick grasp and a good power of combination play an important part. If a blind person goes to the theatre, and his companion describes the scene to him when the curtain rises, he is able to imagine what happens on the stage, and to understand the play.

Like the hand, the human voice can convey fine shades of personality; without asserting that this holds good for every case, we may say that through the voice and the way of speaking a blind man gets to know something about the speaker's features. I have myself experienced the most surprising examples of this.

Though the ear is of great importance in helping the blind to adapt themselves to their surroundings, it lets them down in estimating distances. Tests with others and with myself have convinced me that distances of more than about 10 yards cannot be estimated correctly, and still less in it possible to judge height, as has been proved by tests with church bells, sounds of masonry on different storeys of a building, and other noises from above. Consequently, the blind cannot imagine accurately any extent except when it is relatively small.

It is out of the question for them to form an approximately correct idea of a large square, even when they walk all around it, or of the inside of a theatre. But this does not detract from the importance of the ear for the blind.

The third substitute function is the sense of smell. It is of minor importance, but serves as a good guide in cases when a blind person walks without a companion. In places known to him the smells issuing from different shops are a great help. A blind friend, who came to see me often, found the house, which was the third from a corner with a grocer's shop, by the smell of it, and in another case known to me a baker's shop served the same purpose. The importance of the sense of smell is emphasized by a letter I received from a deaf and blind friend:

A great misfortune has happened to me, as I have lost my sense of smell. It is only now that I feel really helpless. 


\section{The Deaf AND Blind}

Fortunately there are not too many suffering from this double infirmity, though their number is great enough. Up till now their number has not been correctly fixed by statistics in any country. There are not many persons born deaf and blind, nor many deaf and blind children, for in most cases the deafness occurs later in life.

How do we communicate with these people? When they know Braille, which is often the case, communication is easy. With those who had learned to write before they became blind, one can write in their hand, which they like. But there are other special methods of communication.

The oldest method, no longer in use, is for the deaf and blind person to put the fingertips of one hand on the lips of the speaker and the other hand on the larynx. In this way he is able to recognize the sounds through the difference in movements and vibrations, but this is very difficult and unpleasant to operate.

Of the other existing methods (touch-alphabets) there are two good ones in use:

(1) The deaf and blind person wears a glove on which the characters have been arranged in a manner known to him, and the "speaker" then has to touch any character wanted. In this way the seeing man has nothing special to learn. Much practice brings good results.

(2) Of the other touch-alphabets, which are more or less similar, the Lorm system is the best. It is named after the Austrian poet Hieronymus Lorm (1821-1902), who with his daughter invented this system when he became blind and deaf late in life. The characters are indicated by taps and strokes on the back of the hand or on the palm. It is so simple and clear that after only a little practice a fluent conversation is possible. There is still a very important psychological trait, for the taps and strokes express something individual, just like the voice, and so the deaf and blind person recognizes his companion at the very first characters. For trained "Lormers" there is no difficulty in transmitting and understanding books and newspapers or lectures, or even the conversation of the persons in the room. I myself have often been the interpreter in such cases.

It must be added that the deaf and blind can speak normally, but owing to lack of control their speech usually becomes indistinct.

The above-mentioned resources enable the deaf and blind to achieve a normal mental development.

It is a matter of course that teaching deaf and blind children, who have never had either optical or acoustical impressions, is very difficult, especially at the beginning, and also later on when abstractions have to be explained. This requires great patience on the part of the child, and the system is too intricate to be described here.

But what of the power of observation and the capacity of orientation in cases 
where the hand cannot be used as the substitute for the eye and the ear? Now we come to the point of having to treat further details of the sense of feeling. The achievement of the sense of feeling is not based only on the efficiency of the hand and the fingers, but the skin of the entire body can be trained to a very high degree of sensitiveness. This involves a sensitiveness existing for objects in one's immediate neighbourhood. The best name for this faculty is the French sens de l'obstacle and the German Fernempfinden or Tiefensinn der Haut.

The whole matter is not new, for Petrarch and Goethe wrote about similar tests in the dark.

What exactly the sens de l'obstacle means, is not yet known to us. The first tests, taken by the teachers Kunz and Truschel of the Institutes for the Blind at Illzach and Strasbourg (Alsace), go back as far as 1886. Both mention the ear and "something else which cannot be defined further". Later tests even speak of a sixth sense characteristic of the blind. All experiments resulted in proving that the persons had an accurate sensitivity for objects near them. Professor Hanselmann of the Heilpädagogische Seminar at Zürich and Professor Erismann of the Psychologische Institut at Innsbruck have arrived at the same results with their latest tests. They have experimented with blind persons and have correctly concluded that the sens de l'obstacle is situated in the ear. But none of their experiments were made with deaf and blind people, as far as I know. I have worked with such persons, in whom the sense of hearing was lacking, and found that they all reacted to objects near them, e.g. walls, furniture, trees, and even openings in the wall, etc. This proves the existence of another agent of perception besides the ear. Though psychologists and neurologists have studied this problem, the nature of the sens de l'obstacle has not yet been found. Some neurologists mention possible waves in the ether unknown to the normal person. It is a fact that the persons tested acknowledged a sense of oppression. Not long ago a deaf and blind man used the words: "when I feel somebody near me ....".

The sens de l'obstacle can be situated in any part of the body. As for myself it is strongest in the upper arms, the skull, and the feet. Generally the sensitivity is very strong in the feet. I practised with a blind and deaf girl in Amsterdam, who always held her hands stretched out in front of her, as so many blind persons do, and her movements were very unsteady. When I advised her to hold her hands behind her back and to note the sens de l'obstacle of the whole body and especially of the feet, the results were astonishing. All my test convinced me that besides the ear some other sense must function.

It is important to pay attention to the sens de l'obstacle, because it influences the movements and attitudes of blind people making them more steady and supple.

Thus the coordination of the substitute functions enables the blind to 
adapt themselves to the world of the seeing; they lose the handicap which marks them as " blind", and are delivered from the isolation which compels them to live in the periphery of society. That is of the greatest importance, as the new methods of care for the blind aim at finding suitable occupations where they can work amongst the seeing as one of them. Besides those pursuing a profession and applying themselves to music, many blind persons work as telephonists and short-hand typists, or as craftsmen in factories. Many women are trained as housekeepers, and learn besides weaving and knitting, to clean, to cook, to sew by hand as well as with a sewingmachine, and even to iron. I myself know several women who perform their task as housekeepers and mothers very well. Even deaf and blind men and women have succeeded in this respect.

It may be possible for the blind to consider their blindness not as an irretrievable calamity, but as a misfortune which can be overcome through the development of the substitute functions, and life is thus made easier to bear and can be more or less successful even for the blind and deaf. 